\title{
Expression of Concern: Aspirin attenuates insulin resistance in muscle of diet-induced obese rats by inhibiting inducible nitric oxide synthase production and $S$-nitrosylation of IR $\beta /$ IRS-1 and Akt
}

\author{
M. A. Carvalho-Filho ${ }^{1}$ - E. R. Ropelle ${ }^{1}$ • R. J. Pauli ${ }^{1}$ - D. E. Cintra ${ }^{1}$ • D. M. L. Tsukumo ${ }^{1}$ \\ L. R. Silveira ${ }^{1}$ - R. Curi $^{1}$ - J. B. C. Carvalheira ${ }^{1}$ - L. A. Velloso ${ }^{1}$ - M. J. A. Saad ${ }^{1}$
}

(C) Springer-Verlag Berlin Heidelberg 2017

Expression of Concern to: Diabetologia

DOI 10.1007/s00125-009-1498-1

On the basis of the recommendation of the EASD's Scientific Integrity Panel, the Editor-in-Chief is issuing this expression of concern to alert readers to questions about the reliability of some of the data in the article cited above.

In particular, it appears that the bands for $\alpha$-tubulin in Fig. $4 \mathrm{~b}$ are the same as the first three bands for total p70S6K in Fig. 6k in Ropelle ER et al (2008) (A central role for neuronal AMP-activated protein kinase (AMPK) and mammalian target of rapamycin (mTOR) in high-protein diet-induced weight loss. Diabetes 57(3): 594-605. DOI:10.2337/db07-0573).
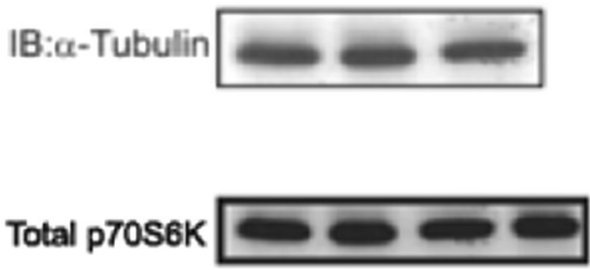

The online version of the original article can be found at http://dx.doi.org/ 10.1007/s00125-009-1498-1

M. J. A. Saad

msaad@fcm.unicamp.br

1 FCM-UNICAMP,

Rua Tessália Vieira de Camargo, 126,

Cidade Universitária Zeferino Vaz,

Campinas, São Paulo 13083-887, Brazil
The journal has been unable to obtain the high resolution image used in Ropelle et al from the corresponding author, Dr Carvalheira, and the editorial office of Diabetes no longer had a copy of this image. It has therefore not been possible to use image forensics to conclusively confirm or refute this concern.

In line with guidelines issued by the Committee on Publication Ethics (COPE), the journal has informed the corresponding author, Mario Saad, of this concern. The University of Campinas (São Paulo, Brazil) was asked, in March 2016, to undertake an institutional investigation. As no results from this investigation have been forthcoming this expression of concern is being issued to alert readers to exercise caution when interpreting the content and conclusions of this article. This expression of concern will remain in place until such a time as further evidence is available. 